\title{
Complutum
}

ISSN: 1131-6993

\section{José Luis González Arpide (Madrid, 1953-León, 2019)}

Luis Ángel Sánchez Gómez ${ }^{1}$

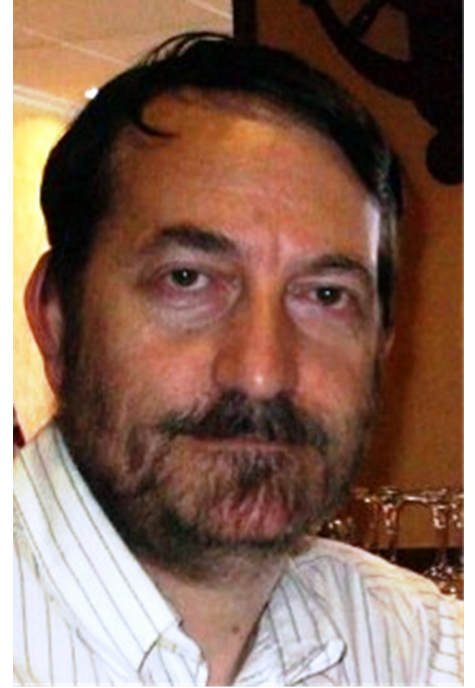

José Luis González Arpide fue mi profesor de Etnología en la antigua licenciatura en Historia, en la Facultad de Geografía e Historia de la Universidad Complutense, en el curso de 1980-81, durante el segundo año de la carrera. Formaba parte del antiguo Departamento de Prehistoria, hoy refundido en el de Prehistoria, Historia Antigua y Arqueología. Creo recordar que entonces, en el plan de estudios de 1976, la asignatura era obligatoria para todos los que habrían de optar por la especialidad de Historia, que éramos la mayoría; no la cursaban, por tanto, ni los de Geografía ni los de Arte.

Arpide, como era conocido por todos, había comenzado su vinculación con la Complutense en enero de 1978, como "profesor encargado de curso" (los famosos profesores no numerarios, o PNN) de uno de esos grupos; luego fueron dos $\mathrm{y}$ al final nada menos que cinco. Ese último curso, el de 1982-83, lo asumió como "catedrático interino", cargo al que renunció en el mes de noviembre para trasladarse a la Universidad de
León, donde obtuvo plaza de titular en 1987, en el Departamento de Historia.

Debo reconocer que mi vinculación con Arpide quedó circunscrita a unos pocos años, aunque fue intensa y, sobre todo, decisiva. En otoño de 1979 comencé a estudiar la licenciatura de Historia en la Complutense sin plantearme en realidad cuál podría ser la utilidad "práctica" de la carrera, pero sí teniendo claro (o eso creía) que me habría de decantar por la especialidad de Historia Contemporánea. Sin embargo, Arpide y su asignatura de Etnología trastocaron todos mis planes.

Como el número de alumnos era muy elevado, Arpide organizaba el curso con un par de clases iniciales introductorias, a las que seguían reuniones con los grupos creados para la elaboración de los trabajos que permitirían calificar la asignatura. Proponía dos tipos de trabajos: de síntesis bibliográfica sobre ciertas comunidades (entonces todavía estaba de moda el estudio de los "pueblos malditos" de la Península Ibérica) y de campo. También distribuía apuntes sobre teoría e historia de la antropología que, creo recordar, tenían como base esencial los estudios de Marvin Harris. Mi grupo se decantó por un trabajo de campo. Tan interesante y positivo fue todo, que cambié por completo el diseño de la carrera y decidí que seguiría la especialidad de Prehistoria, por la única y absurda razón de que incluía una asignatura de Etnología de la Península Ibérica, que ya no cursé con Arpide.

Aunque solo fui alumno de José Luis durante aquel curso de 1980-81, los dos años siguientes seguimos manteniendo una estrecha relación. Bajo su dirección, y junto con unos pocos compañeros "románticos" amantes de la Etnología, elaboramos dos números de unos Cuadernos de documentación etnológica que recogían información bibliográfica ordenada

\footnotetext{
Dpto. de Prehistoria, Historia Antigua y Arqueología

Facultad de Geografía e Historia

Universidad Complutense de Madrid
} 
por temas y que un muy entusiasta Arpide pretendía incluso poner a la venta.

Como digo, el entusiasmo que ponía José Luis en todo lo que hacía y nos proponía era proverbial, y eso a pesar de que su carácter y sus maneras eran extremadamente reposadas. Además, a todos nos llamaba la atención su interés por las nuevas tecnologías, circunstancia que alcanzó su momento cumbre cuando nos mostró y puso en funcionamiento un aparato absolutamente extraordinario: un ordenador ZX Spectrum, que guardaba la información nada menos que en cintas de casete.

Tanto para sus alumnos como para sus colegas Arpide fue siempre "el de los tabarquinos", por su tesis doctoral defendida en 1979 sobre los pobladores de la isla de Tabarca. No obstante, debo recordar que a ese doctorado en Geografía e Historia por la Complutense se sumaban las licenciaturas en Periodismo por la misma universidad y en Antropología Social por la Universidad Jussieu-París VII, que desde 1994 lleva el nombre de Denis Di- derot. Aunque continuó publicando trabajos sobre la historia y las gentes de tan singular enclave isleño, se interesó también por otros temas, vinculados sobre todo con el ámbito leonés. En este terreno, su trabajo más conocido es quizás el censo y catálogo de hórreos leoneses publicado en 1987 en la revista Kobie. Su salida de la Universidad Complutense y mi interés por temas poco o nada relacionados con los que él había estudiado, y estudiaría, hicieron que el vínculo, lamentablemente, acabara diluyéndose.

Termino ya, y lo hago advirtiendo de que no he pretendido redactar una nota necrológica, ni una valoración de la obra académica de Arpide. Mi intención ha sido únicamente recordar con afecto a la persona que se ha marchado demasiado pronto y al docente "culpable" de que hoy yo también lo sea, impartiendo, además, la misma asignatura que él me dio a conocer y que encauzó mi actividad profesional por un territorio que hasta entonces me había resultado completamente desconocido. Gracias, José Luis. 